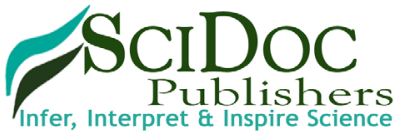

International Journal of Microbiology \& Advanced Immunology (IJMAI) ISSN:2329-9967

\title{
Innovative Approaches to Upgrade Functional Properties of Dahi
}

Editorial

S. Sarkar

Quality Assurance, Metro Dairy Limited, Barrackpore-Barasat Link Road, Subhasnagar, P.O. Neelgunj Bazar, Kolkata-700121, West Bengal, India.

Fermentation is the oldest method of milk preservation. Dabi is considered the oldest Indian fermented milk product and is equivalent to western yoghurt obtained by lactic fermentation through the action of single or mixed strains of lactic acid bacteria or by lactic fermentation accompanied by alcoholic fermentation by yeast. Traditionally dahi was prepared at home and it is one of the fastest growing milk product segments in India.

Dahi could be categorized as a functional food owing to its various nutritional and therapeutic properties. Nutritional components of milk such as vitamins, proteins, minerals, carbohydrates are modified under the influence of metabolic activity of starter cultures during fermentation. $\beta$-galactosidase, the enzyme required for lactose hydrolysis have been demonstrated in dabi and the product exhibited antagonism against pathogenic and spoilage causing microorganisms.

Yoghurt obtained by lactic acid fermentation through the action of Lactobacillus delbrueckii subsp. bulgaricus and Streptococcus thermophilus is worldwide popular due to its nutritional and therapeutic significance. Conjugation application of yoghurt cultures along with normal dahi cultures resulted in more acceptable product in terms of body, texture and flavour and greater antibacterial activity against pathogenic organisms.
With the growing inclination of consumers towards healthful foods, attempt has been made to supplement traditional fermented milk products with probiotic cultures to enhance its dietetic value. Recently, attempts have been made to include certain probiotic and beneficial bacteria such as Lactobacillus acidophilus, Lactobacillus casei, Lactococcus lactis, Bifidobacterium bifidum etc. with the objective of enhancing the dietetic properties of traditional dabi. Animal feeding trials revealed significant reduction in myeloperoxidase, $\beta$-glucoronidase activity and improved disease activity scores and offer effective adjunctive treatment for management of ulcerative colitis, delayed the onset of glucose intolerance, hyperglycemia, hyperinsulinemia, dyslipidemia, and oxidative stress indicating a lower risk of diabetes and its complications, prevention of colorectal carcinogenesis, decline in plasma total cholesterol and triglycerides.

Attempt has also been made to enhance the antagonistic activity of probiotic dabi against pathogenic indicator with the inclusion of different herbs such as betel leaves, mint leaves, ajwain and garlic. Substitution of skimmed milk with coconut milk and inclusion of fruit pulp or banana juice are recommended to enhance the dietetic value of traditional dabi. Consumption of probiotic dahi as a functional food is recommended.

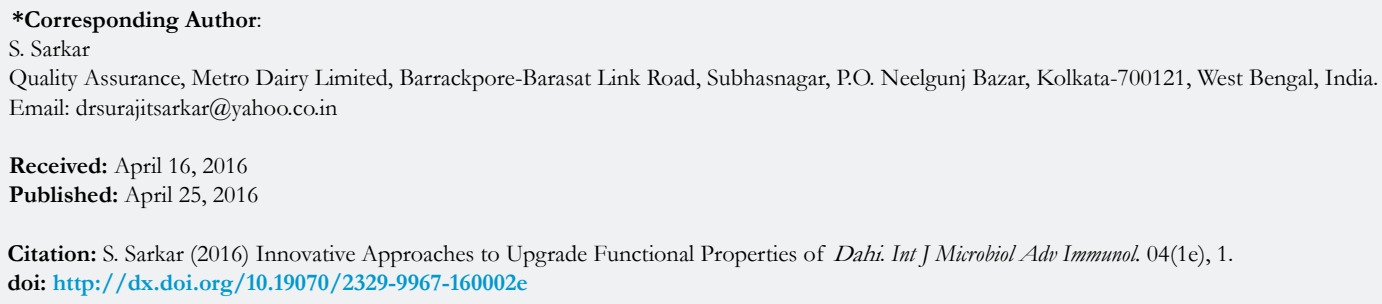

Copyright: S. Sarkar ${ }^{\circ}$ 2016. This is an open-access article distributed under the terms of the Creative Commons Attribution License, which permits unrestricted use, distribution and reproduction in any medium, provided the original author and source are credited. 